DOI: $10.2478 / \mathrm{v} \cdot 10169-011-0026-0$

\title{
OPTIMISED MIX DESIGN FOR NORMAL STRENGTH AND HIGH PERFORMANCE CONCRETE USING PARTICLE PACKING METHOD
}

\author{
S. GOPINATH ${ }^{1}$, A. RAMACHANDRA MURTHY ${ }^{1}$, D. RAMYA ${ }^{1}$, \\ NAGESH R. IYER ${ }^{1}$
}

\begin{abstract}
This paper presents the details of optimized mix design for normal strength and high performance concrete using particle packing method. A critical review of mix design methods have been carried out for normal strength concrete using American Concrete Institute (ACI) and Bureau of Indian Standards (BIS) methods highlighting the similarities and differences towards attaining a particular design compressive strength. Mix design for M30 and M40 grades of concrete have been carried out using ACI, BIS and particle packing methods. Optimization of concrete mix has been carried out by means of particle packing method using EMMA software, which employs modified Anderson curve to adjust the main proportions. Compressive strength is evaluated for the adjusted proportions and it is observed that the mixes designed by particle packing method estimates compressive strength closer to design compressive strength. Further, particle packing method has been employed to optimize the ingredients of high performance concrete and experiments have been carried out to check the design adequacy of the desired concrete compressive strength.
\end{abstract}

Key words: Normal strength concrete, High performance concrete, ACI method; BIS method; Particle packing; Mix design; Compressive strength.

\section{INTRODUCTION}

Concrete is a composite material with heterogeneous properties that are vitally dependent on the amount and properties of the constituent phases. The mix design is an essential tool in all aspects of concrete technology and its prime objective is to achieve the required functional properties at the minimum cost, under consideration of environmental parameters and planned production technique. Well-developed mix design methods are thus prime tools in securing sustainable industrial concrete construction techniques. Emerging new knowledge from research such as high performance concrete, recycled aggregate concrete, self-compacting concrete etc., and modern information technology solutions indicate the need of further development of established mix design methods. The necessary first step to be taken to design a concrete mix is to establish clearly the requirements that the mix design must meet. These generally include one

${ }^{1}$ CSIR - Structural Engineering Research Centre, Taramani, Chennai-600113, India, e-mail: smithag@serc.res.in, smithagopinath13@yahoo.com 
or more of the following: mechanical strength, durability, characteristics of concrete member, and special requirements specified by the project design. The proportioning of ingredient of concrete is governed by the required performance of concrete in two states, namely, the fresh and the hardened states. If the fresh concrete is not workable, it cannot be properly placed and compacted. Hence the workability is a factor of vital importance. The compressive strength of hardened concrete is generally considered to be an index of its other properties, which depends upon many factors, e.g. quality and quantity of cement, water and aggregates; batching and mixing; placing, compaction and curing.

Many of the existing methods for mix design in the different countries are different but are based on a similar basic approach. Empirical relationships, charts and graphs were developed from extensive experimental investigations. Following methods are in general practice:

1. ACI Mix design method

2. USBR Mix design method

3. British Mix design method

4. Mix design method according to Indian standard

ACI Mix design method is an originator for all other methods, including Indian standard method. The method suggested by the ACI Committee- 211 [1] are widely used in the USA. One method is based on the estimated weight of the concrete per unit volume. The other method is based on calculation of the absolute volume of concrete ingredients. The ACI methods take into consideration the requirements for workability, consistency, strength and durability.

The subject of optimizing the concrete composition by selecting the correct amounts of various particles has already aroused interest for more than a century (Johansen et al., [2], Goltermann et al., [3], Jones et al., [4]). Particle Packing was first used in concrete research in 1892 by Feret to optimize aggregate gradation (Wang [5]) and initial objective was to achieve most dense packing possible in order to reduce cement usage. It is generally agreed that concrete performance can be improved by reducing capillary-sized voids and their interconnectivity. Particle packing models, that are used to estimate the packing density/voids ratio of the solid combinations, can provide tools to improve the performance of concrete by proportioning the mix constituents in such a way as to provide the maximum packing density of the solid combinations, while ensuring that the concrete is sufficiently workable. Effective studies using particle packing method for high performance concrete were reported by Manu Santhanam [6].

In this paper, application of particle packing method for normal strength and high performance concrete have been explained. A critical review of mix design methods using American concrete institute (ACI) and Bureau of Indian Standards (BIS) have been outlined. Mixes of M30 and M40 grades of concrete have been designed using ACI and BIS methods and these mixes have been optimized using particle packing method. Experimental investigations have been carried out to find out the compressive 
strength of all mixes. Further, the applicability of particle packing method for high performance concrete have been demonstrated.

\section{Review of Mix Design Methods}

The following section presents brief details about ACI and BIS mix design procedure.

\subsection{ACI-318 (2002) METHOD}

In 1991, ACI published its guidelines for normal, heavyweight and mass concrete mix design [ACI Committe211, [1] (reapproved in 2002)]. The Absolute Volume Method of mix design as described by the ACI Method (Kosmatka et al., [7]) is revised, and the design steps for mix proportioning as recommended by ACI Committee 211, are discussed.

This method is based on determining the coarse aggregate content based on, dry rodded coarse aggregate bulk density and fineness modulus of sand. This method takes into account the actual voids in compacted coarse aggregates that are to be filled by sand cement and water. This method also gives separate tables for air-entrained concrete. This method is most suitable for design of air-entrained concrete. This method gives separate values of water and sand content for maximum size of aggregate up to $150 \mathrm{~mm}$. Hence this is most suitable method for designing plum concrete. It also gives separate values for size less than $12.5 \& 25 \mathrm{~mm}$ down coarse aggregate.

This method has the following limitations:

a. It gives coarse aggregate contents for sand with Fineness modulus (FM) range of 2.4 to 3.0. It is found that sand available in many parts of India is extremely coarse with FM more than 3.2.

b. In this method the density of fresh concrete is not given as function of specific gravity of its ingredients. In BIS and British Department of environment (DOE) method the plastic density or yield of concrete is linked to specific gravity of ingredients.

c. The values of density of fresh concrete given in this method range from 2285 $\mathrm{kg} / \mathrm{m}^{3}$ for size less than $10 \mathrm{~mm}$ aggregate to $2505 \mathrm{~kg} / \mathrm{m}^{3}$ for size less than $150 \mathrm{~mm}$ coarse aggregate. It is found that in many parts of our country, the density of fresh concrete (plastic density) of 20 and $10 \mathrm{~mm}$ down aggregates vary from 2400 to $2600 \mathrm{~kg} / \mathrm{m}^{3}$. The weights calculated from the given densities often result in higher cement contents than that assumed.

d. The ACI method also does not take into account the effect of the surface texture and flakiness of aggregate on sand and water content, neither does it distinguish between crushed stone aggregates and natural aggregates.

e. The ACI method does not have a specific method of combining $10 \mathrm{~mm}$ aggregates with $20 \mathrm{~mm}$ aggregates. 
f. The fine aggregate content cannot be adjusted for different cement contents. The richer mixes and leaner mixes may have same sand proportion, for a given set of materials.

The procedure for mix design of concrete using ACI method is given below.

1. The required (target) average compressive strength $\left(\overline{f_{c r}^{\prime}}\right)$ at 28 days for mix design is determined by adding up an empirical factor $(\mathrm{k})$ to the design compressive strength $\left(f_{c}^{\prime}\right)$ as per Eq. (2.1) given below:

$$
\overline{f_{c r}^{\prime}}=f_{c}^{\prime}+K
$$

2. The w/c ratio is selected based on the target strength and the type of concrete (air-entrained or non air-entrained).

3. Air content, as percentage of the concrete volume, is estimated depending upon the air-entrained or non-air-entrained type of concrete, exposure conditions, and nominal maximum size of aggregate (NMSA).

4. Slump, as measure of workability, is selected depending upon the type of structure and complexity of the pouring conditions.

5. Water content, is determined based on the NMSA, type of concrete (air-entrained or non-airentrained), and specified slump. Then it is adjusted for the types of aggregates.

6. Cement content, is calculated based on the w/c ratio and the water content.

7. Coarse aggregates content, as dry rodded bulk (percentage) of concrete unit volume, is determined based on the NMSA, and the fineness modulus of sand.

8. Once the water content, cement content, air content, and the coarse aggregate content per unit volume of the concrete is determined, the fine aggregate (F.A) is calculated by subtracting the absolute volume of the known ingredients from unit volume of the fresh concrete (in this case $1 \mathrm{~m}^{3}$ ) as following:

$$
F \cdot A=1-Y
$$

where,

$\mathrm{Y}=$ sum of all other ingredients (air, water, cement and coarse aggregates) in cubic meter calculated for $1 \mathrm{~m}^{3}$ of concrete.

9. Finally, water content is adjusted based on the absorption and the current moisture content of the coarse and fine aggregates, in account of saturated surface dry condition of the aggregates.

\subsection{Old BIS Method (IS- 10262(1982))}

The BIS method considers normal mixes (up to M35) and high strength mixes (M60 and above) differently. This is logical because richer mixes need lower sand content when compared with leaner mixes. The method also gives correction factors for different $\mathrm{w} / \mathrm{c}$ ratios, workability and for rounded coarse aggregate. In BIS method, the quantities of 
fine and coarse aggregate are calculated with help of yield equation, which is based on specific gravities of ingredients. Thus density of concrete calculated from yield equation is generally expected to be closer to actual density obtained in laboratory, provided specific gravities are calculated accurately. Thus actual cement consumption will be close to that targeted in the first trial mix itself. The water cement ratio is calculated from cement curves based on 28 days strength of cement. This can be time consuming and impractical at times. The BIS method gives separate graphs using accelerated strength of cement with reference mix method. This greatly reduces the time required for mix design.

The BIS method has the following limitations:

a. The BIS method recommends $35 \%$ sand content by absolute volume for zone II sand with correction of $+1.5 \%$ for zone I and $-1.5 \%$ for zone III. These zones have wide range and this correction is not adequate to achieve a cohesive mix. Some times a correction may be required even when fine aggregate varies from upper side to lower side of a particular zone.

b. Though sand content is adjusted for lower water cement ratio there is no direct adjustment for cement content. The cement particles act, as fines in concrete and richer mixes often require lesser fine aggregate when compared to leaner mixes. A mix in which cement content is lowered by use of plasticizers may require higher sand content to improve cohesion.

c. The BIS method gives different tables for determining sand content for concrete up to M 35 grade and above M 35 grade. There is an abrupt change in sand content from $35 \%$ to $25 \%$ in the two tables when shifting from M 35 grade concrete to M40 grade concrete. The change may be justified to account for higher cement content but it should be gradual in nature.

d. The BIS method considers compaction factor as measure for workability, to calculate the water demand. Compaction factor may not correctly represent workability and the revised IS 4562000 has excluded compaction factor as a measure of workability. It recommends use of slump as a measure for workability. Relationship between slump and compaction factor is difficult to standardize.

e. The BIS method does not take into account the effect of the surface texture and flakiness of aggregate on sand and water content. It does not recommend any corrections when crushed fine aggregate is used against natural fine aggregate as in case of Department of Environment (DOE) method.

f. The BIS method does not easily account for blending of different fine aggregates or coarse aggregates when they individually do not conform to IS requirements. On the other hand in Road Research Laboratory (RRL) method, coarse sand can be blended with fine sand or stone dust to get the required gradation (Natural sand and stone dust will have different specific gravities). Even coarse aggregates of different sizes, gradation and specific gravities can be blended to achieve the required gradation in RRL method. 
g. The BIS method gives water demand and fine aggregate content for $10 \mathrm{~mm}$, $20 \mathrm{~mm}$ and $40 \mathrm{~mm}$ down aggregate. In practice, the maximum size of coarse aggregate is often between $20 \mathrm{~mm}$ and $40 \mathrm{~mm}$, the estimation of water and sand content is difficult.

$\mathrm{h}$. The quantities of fine aggregate and coarse aggregates are calculated from the yield equation. The yield equation is based on concept, that volume of concrete is summation of absolute volumes of its ingredients. Absolute volume of ingredients are function of specific gravities of ingredients. The plastic density of concrete if theoretically calculated on the basis of specific gravities, may not match with that actually measured from concrete.

i. The BIS method does not have a specific method of combining $10 \mathrm{~mm}$ aggregates with $20 \mathrm{~mm}$ aggregates. The grading limits for combined aggregates in IS:383 are too broad and do not help much to arrive at particular ratio of different coarse aggregates. The combined grading curves of RRL method help us to arrive on particular ratio of coarse aggregates.

j. The BIS method does not have an adjustment in fine aggregate content for different levels of workability. Higher workability mixes require more fine aggregate content to maintain cohesion of mix.

The steps to be followed for designing a mix using BIS:

The BIS has recommended guidelines for concrete mix design based on cement and other materials locally available in India (SP:23-1988 [8], IS10262 [9], IS 10262-[10]).These guidelines are applicable for normal concrete (less than $60 \mathrm{MPa}$ ) mix design. Use of gap graded aggregates, various admixtures, and pozzolana is beyond the scope of IS 10262-1982. The design steps for mix proportioning as recommended in IS 10262-1982, are discussed below: 1. The target average compressive strength $\overline{\mathrm{f}_{\mathrm{ck}}}$ at 28 days is determined by using Eq (2.3):

$$
\overline{f_{c k}}=f_{c k}+s t
$$

where, $\mathrm{f}_{c k}=$ characteristic compressive strength at 28 days, $\mathrm{s}=$ standard deviation of compressive strength, $\mathrm{t}=\mathrm{a}$ statistic, depending upon the accepted proportion of low results and the number of tests.

2. The water cement (w/c) ratio is chosen from an empirical relationship (a graph) for the given 28-day target mean strength. The w/c ratio is checked against the limiting $\mathrm{w} / \mathrm{c}$ ratio to satisfy the durability requirements.

3. Air content, amount of entrapped air in fresh concrete, as percentage of volume of concrete, is estimated based on the NMSA.

4. Initially, water content, as mass $(\mathrm{kg})$ per unit volume $\left(\mathrm{m}^{3}\right)$ of concrete, is selected based on the target strength. Then, the initially determined water content is adjusted for workability conditions depending upon the compacting factor and types of aggregates.

5. Sand content, as percentage of total aggregate volume, is selected based on the NMSA and the target strength. Then, the initially determined sand content is adjusted for workability conditions depending upon the sand grading zone, w/c ratio, and type of aggregates. 
6. The cement content is calculated from the w/c ratio and the water content. The cement content, thus calculated, is then checked against the minimum cement content to satisfy the durability requirement.

7. With the quantities of water and cement per unit volume of concrete and the percentage of sand in the total aggregate already determined, the coarse and fine aggregate contents per unit volume of concrete are calculated from the following equations, respectively:

$$
\begin{gathered}
C_{a}=\left[1000 V-w+\frac{C}{S_{c}}\right] S_{c a}(1-P) \\
f_{a}=\left[1000 v-w+\frac{C}{S_{c}}\right] P S_{f a}
\end{gathered}
$$

where,

$\mathrm{C}_{a}=$ total mass of coarse aggregate, $\left[\mathrm{kg}\right.$ per $\mathrm{m}^{3}$ of concrete],

$\mathrm{f}_{a}=$ total mass of fine aggregate, [kg per $\mathrm{m}^{3}$ of concrete],

$\mathrm{V}=$ absolute volume of fresh concrete, equal to gross volume minus the volume of entrapped air,

$\mathrm{W}=$ mass of water $(\mathrm{kg})$ per $\mathrm{m}^{3}$ of concrete,

$\mathrm{C}=$ mass of cement $(\mathrm{kg})$ per $\mathrm{m}^{3}$ of concrete,

$\mathrm{S}_{c}=$ specific gravity of cement,

$\mathrm{p}=$ ratio of fine aggregate to total aggregate by absolute volume,

$\mathrm{S}_{f a}=$ specific gravities of saturated surface dry fine aggregate,

$\mathrm{S}_{c a}=$ specific gravities of saturated surface dry coarse aggregate.

8. Finally, water content is adjusted based on the absorption and the current moisture content to generate equivalent of saturated surface dry condition of the aggregates.

\subsection{New BIS Method (IS- 10262(2009))}

The Bureau of Indian Standards (BIS) has released the final code on concrete mix proportioning in December 2009. The new code is used for designing concrete mixes using both mineral and chemical admixtures. The durability requirements, limitations on w/c ratio and maximum cement contents are as per IS 456:2000. The BIS and ACI methods use Eq. (2.3) and Eq. (2.1) respectively to determine the target average compressive strength. Although both methods utilise standard deviation to calculate the target strength, techniques of calculation is not the same. When sufficient data are not available to establish standard deviation, the ACI method recommends empirical values to determine the target calculating strength. On the other hand, the old BIS method suggests the value of standard deviation to be based on the quality control. In the new BIS method, standard deviation is to be calculated separately for each grade of concrete. When sufficient test results for a particular grade of concrete are not available, 
the value of standard deviation given in the code may be assumed for the first trial mix. Regarding the requirements for selecting w/c ratio, water content and estimating coarse aggregate content and fine aggregate content have been modified accordingly in the new BIS code. Considering that the air content in normal concrete (non air entrained concrete) is not of much significance, the consideration of air content has been deleted. The old BIS Method uses the compacting factor as a measure of workability, whereas the new BIS and ACI use the slump. Regarding w/c ratio, the new BIS suggests that the w/c curve has to be developed based on the type of materials to be used in the project. The water content can be determined independent of target strength, whereas in the old BIS method, target strength influences the water content. The new BIS is similar to ACI method wherein a table for maximum water content per cubic meter of concrete for nominal maximum size of aggregate. The new BIS procedure is same as that of ACI method, wherein the volume of coarse aggregate per unit volume of total aggregate for different zones of fine aggregate is calculated based on maximum size of aggregate.

\subsubsection{Packing Theory}

Several models have been presented in the literature on particle packing to obtain high (or low) density. Proper design of the particle size distribution is essential in obtaining a dense particle packing. The two classical equations for particle size distributions are those of Furnas [14], Anderegg [15] and Andreassen[16]. In particle packing theory, the particle size distribution (PSD) of the materials used is presented as cumulative finer fraction. The PSD of the sands and gravel is determined by sieving, but the PSD of cement is determined by laser granulometry if not available then by sieving is done. For normal concrete, most design codes require continuous grading to achieve tight packing. Continuous grading curves range from $250 \mu \mathrm{m}$ to a maximum particle size and are S-shaped in a single-logarithmic graph Applying this grading curve to materials with fine constituents, results in mixes that are poor in cement and that are less workable. Standards, therefore require a minimum content of fine materials $(<$ $250 \mu \mathrm{m})$ in normal concrete. Furnas' approach (1931) considers the addition of smaller and smaller particles, whereas Andreassen's model has the capability of adding coarser and coarser particles.

According to Andreasen's particle packing theory, optimum packing can be achieved when the cumulative PSD obeys the following equation:

$$
P(D)=\left(\frac{D}{D_{\min }}\right)^{q}
$$

$\mathrm{P}(\mathrm{D})$ is the fraction that can pass the sieve with opening $\mathrm{D}, \mathrm{D}_{\min }$ is minimum particle size of the mix. The parameter $\mathrm{q}$ has a value between 0 and 1. A continuous grading of all solids (aggregate and powders) will result in a better workability and stability of the concrete mix applied that accounts for the minimum particle size in the mix 
(Kwan [17,18]). Based on this observation, the modified Andreasen model is defined as given below:

$$
P(D)=\left(\frac{D-D_{\min }}{D_{\max }-D_{\min }}\right)^{q}
$$

The Furnas distribution gives curved lines in a log-log plot, whereas the Andreassen equation gives straight lines. Because the distribution given by Furnas is a theoretical one and that of Andreassen is semi empirical, the latter was much criticized with the consequence that the equation was used less than deserved. One of the main limitations observed is that the distribution implies an infinite distribution with no minimum particle size. Real systems are of course finite, but anyhow the equation may be used as a tool because of its simplicity. To deal with the problem of infinite distribution of the Andreassen distribution, a modified version that the Andreassen and the Furnas distribution was developed. This is called the modified Andreassen distribution or the Dinger and Funk equation. The Eq. (2.7) given below relates the Andreassen equation and the modified Andreassen equation.

$$
\begin{aligned}
& \text { CPFT }=(\mathrm{D} / \text { Dmax })^{\mathrm{q}} * 100 \\
& C P F T=\left(\frac{D-D_{\min }}{D_{\max }-D_{\min }}\right)^{q}
\end{aligned}
$$

where, CPFT: Cumulative percent finer than, D: Particle size, $\mathrm{D}_{\min }$ : Minimum particle size of the distribution, $\mathrm{D}_{\max }$ : Maximum particle size and q: Distribution coefficient (q-value)

As mentioned above, the difference in the equations is that the modified Andreassen equation takes into account a minimum particle size whereas the Andreassen distribution considers an infinite distribution towards smaller and smaller particles. On a logarithmic plot, Andreassen equation gives a straight line, while the modified Andreassen equation gives a downwards curvature.

\section{Analytical and Experimental Studies on Mix design}

Sieve analysis has been carried out for cement, fine aggregate and course aggregate. 100 gram of cement is sieved using $90 \mu \mathrm{m}$ sieve and percentage is found to be $97 \%$. For, sieve analysis of fine aggregate $1000 \mathrm{~g}$ of fine aggregate was sieved using sieves ranging from $4.75 \mathrm{~mm}$ to $150 \mu \mathrm{m}$ and percentage passing was determined. Results are shown in Table 1 . In the case of coarse aggregate $50 \%$ of $20 \mathrm{~mm}$ and $50 \%$ of $12.5 \mathrm{~mm}$ aggregates were taken) $2000 \mathrm{~g}$ is sieved using sieves ranging from $25 \mathrm{~mm}$ to $2.36 \mathrm{~mm}$ and the details of percentage passing have been reported in Table 2. 
Table 1

Sieve analysis of Fine Aggregate.

\begin{tabular}{|c|c|}
\hline Sieve no & \% Passing of F.A. \\
\hline $10 \mathrm{~mm}$ & 100 \\
\hline $4.75 \mathrm{~mm}$ & 90 \\
\hline $2.36 \mathrm{~mm}$ & 60 \\
\hline $1.18 \mathrm{~mm}$ & 30 \\
\hline 600 micron & 15 \\
\hline 300 micron & 5 \\
\hline 150 micron & 2 \\
\hline
\end{tabular}

Table 2

Sieve analysis of Coarse Aggregate.

\begin{tabular}{|c|c|}
\hline Sieve no: in micron & \% Passing of C.A. \\
\hline 25000 & 100 \\
\hline 19000 & 97 \\
\hline 12500 & 80.20 \\
\hline 9500 & 54 \\
\hline 4750 & 10 \\
\hline 2360 & 3 \\
\hline
\end{tabular}

Determination of particle density of different materials are discussed below.

1) Particle density of cement : porosity of cement is taken as $2 \%$ and bulk density of cement is $3125 \mathrm{Kg} / \mathrm{m}^{3}$, then particle density of cement is calculated using the following expression:

Particle density $=$ Bulk density/(1-porosity)

The obtained value of particle density for cement is $3.188 \mathrm{~g} / \mathrm{cm}^{3}$

2) Particle density of Fine aggregate : porosity of F.A. is taken as 0.36 and bulk density of F.A. is $1687.5 \mathrm{Kg} / \mathrm{m}^{3}$, then the

Particle density of F.A. $=1687.5 /(1-.36)=2.636 \mathrm{~g} / \mathrm{cm}^{3}$

3) Particle density of coarse aggregate: porosity of coarse aggregate is taken as 0.2 and bulk density of C.A. is $1630.68 \mathrm{Kg} / \mathrm{m}^{3}$, then the particle density of C.A. $=$ $1630.68 /(1-.2)=2.038 \mathrm{~g} / \mathrm{cm}^{3}$

Further, the mixes have been designed according to ACI method and BIS method for a design compressive strength of $30 \mathrm{MPa}$ and $40 \mathrm{MPa}$. The estimated quantities are reported in Table 3. Compression tests have been conducted on cubes of $100 \times 100 \times 100 \mathrm{~mm}$ size to determine the compressive strength at 3,7 and 28 days. The results obtained are shown in Table 3. From Table 3 it is observed that BIS method is very much on conservative side and there is a large scope of optimizing the mix proportions so that over all construction cost can be minimized without compromising on the strength requirements. 
Table 3

Comparative study of mix proportions and compressive strength for M30 and M40 using different mix design methods.

\begin{tabular}{|c|c|c|c|c|c|c|c|}
\hline \multicolumn{5}{|c|}{ Quantities(kg/m³) } & \multicolumn{3}{|c|}{$\begin{array}{l}\text { Cube Compressive } \\
\text { Strength }\left(\mathbf{N} / \mathbf{m m}^{2}\right) \\
\end{array}$} \\
\hline Mix Design & $\begin{array}{c}\mathrm{C} \\
\text { (Cement) }\end{array}$ & F.A. & C.A. & $\begin{array}{c}\text { W } \\
\text { (Water) }\end{array}$ & 3 days & 7 days & 28 days \\
\hline M40 (ACI) & 473.8 & 888 & 783 & 193 & 24.6 & 34.2 & 50.86 \\
\hline $\mathrm{M} 30(\mathrm{ACI})$ & 398 & 848 & 888 & 191 & 19.46 & 25.17 & 40.37 \\
\hline M30(ACI-Particle Packing) & 380 & 460 & 1300 & 182.4 & 17.82 & 31.97 & 43.81 \\
\hline M30(BIS) & 431.67 & 549.73 & 1198 & 194.25 & 31.13 & 46.35 & 53.21 \\
\hline M30(BIS-Particle Packing) & 360 & 660 & 1199 & 162 & 18.33 & - & 42.07 \\
\hline
\end{tabular}

The mixes designed for M30 and M40 have been adjusted to meet Modified Andersson curve for optimization keeping w/c ratio constant. EMMA software has been used for the study. After adjustment, it is found that there is ample scope for reducing the material for particular design strength. Cubes of $100 \times 100 \times 100 \mathrm{~mm}$ size have been cast using particle packing adjusted mix proportions to determine the compressive strength at 3, 7 and 28days. The results are shown in Table 3. It can be observed that with the optimized material quantities, a particular design compressive strength is achieved. Fig. 1 and Fig. 2 shows the mix design as designed using BIS and adjusted using particle packing and ACI designed and adjusted using particle packing. A comparative study of quantity of material required for M30 design mix is shown in Fig.3 using different mix design methods. Since there is a large difference in the ratio of fine aggregate to coarse aggregate for the mixes designed as per particle packing method, the wokablity was less for this mix compared to that of mixes designed according to BIS and ACI. But this issue can be tackled easily by usage of super plasticizers in the

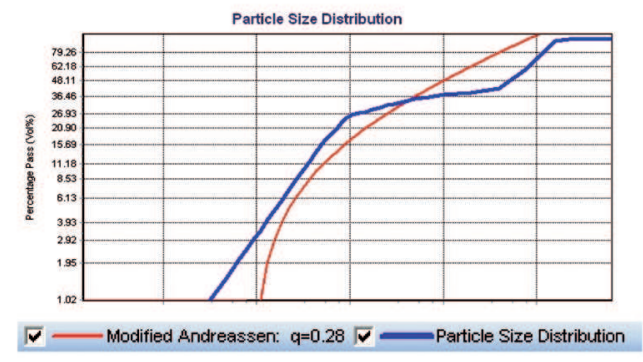

(a)BIS vs Particle Packing (as designed)

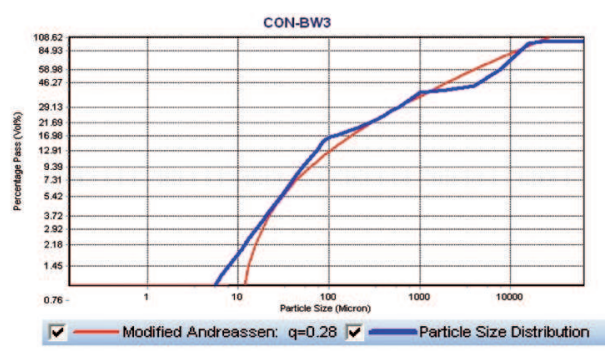

(b) BIS vs Particle Packing (after adjusting)

Fig. 1. BIS mix design (M30) before and after optimization by particle packing. 


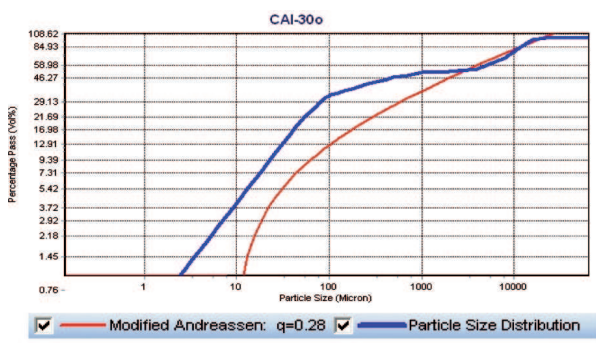

(a) ACI vs Particle Packing

(as designed)

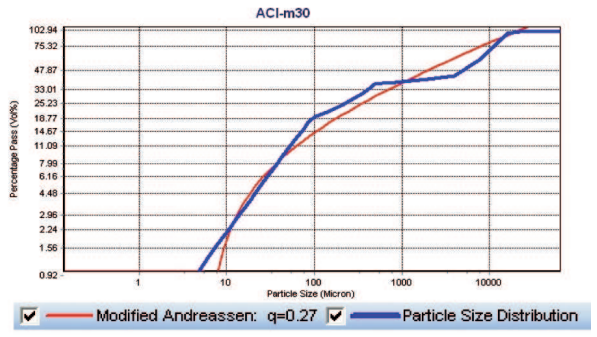

(b) ACI vs Particle Packing

(after adjusting)

Fig. 2. ACI mix design (M30) before and after optimization by particle packing.
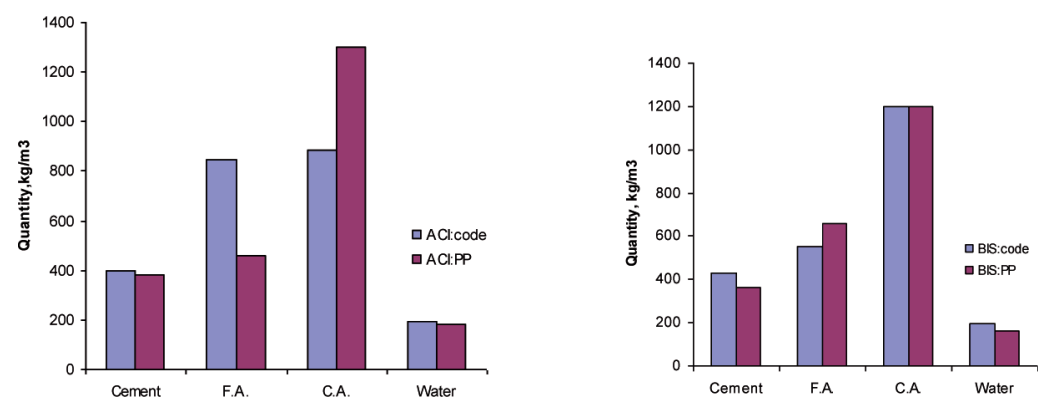

Fig. 3. Comparative study of optimized material estimation with codal provision.

The variation of strength gain using different mix design method is shown in Fig. 4 and it is observed that particle packing has a steady linear trend for strength gain from 3 days to 28days. Further, for M40 grade concrete also, similar studies have been conducted and found that there is a scope for optimizing the mix proportions. Fig. 5 shows the as designed and adjusted proportions for M40 grade concrete using ACI method.

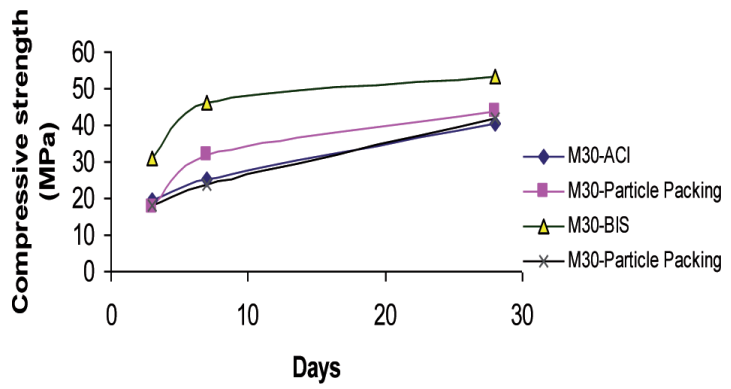

Fig. 4. Strength attainment with Age. 


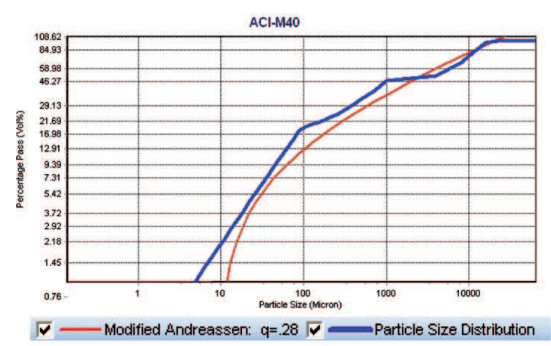

(a) ACI vs Particle Packing(after adjusting)

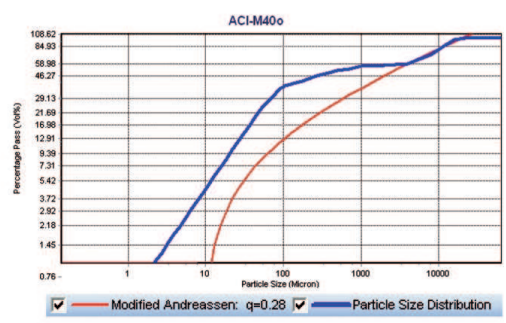

(b)ACI vs Particle Packing (as designed)

Fig. 5. ACI mix design (M40) before and after optimization by particle packing.

\section{Particle packing for High performance Concrete}

The high performance concrete generally contains mineral admixtures of various particle sizes to meet mechanical performance and durability requirements. Scope of present study is limited to determination of compressive strength for an optimized mix design using particle packing method. In order to achieve a desired compressive strength, generally many trial mixes have to be designed and tested. By making use of particle packing making method, the number of trials can be reduced. In the present study, mix for a concrete containing a fine grained matrix has been developed using particle packing method. The mix proportion obtained using particle packing is given in Table 4 . Cubes of $70 \times 70 \times 70 \mathrm{~mm}$ have been cast to determine the compressive strength. The details of grading curve for $\mathrm{q}=0.26$ is shown in Fig. 6 . The compressive strength for 3 , 7 and 28days is shown in Table 5. From this example, it can be concluded that if the mix contains more ingredients, particle packing method based on modified Andersson curve provides the best solution for mix design.

Mix proportion for high performance concrete.

\begin{tabular}{|c|c|}
\hline Mix Design & Quantity $\left(\mathbf{k g} / \mathbf{m}^{3}\right)$ \\
\hline Cement & 420 \\
\hline Fly ash & 170 \\
\hline Silica Fume & 35 \\
\hline Quartz sand & 500 \\
\hline Quartz powder & 450 \\
\hline Water & 280 \\
\hline
\end{tabular}




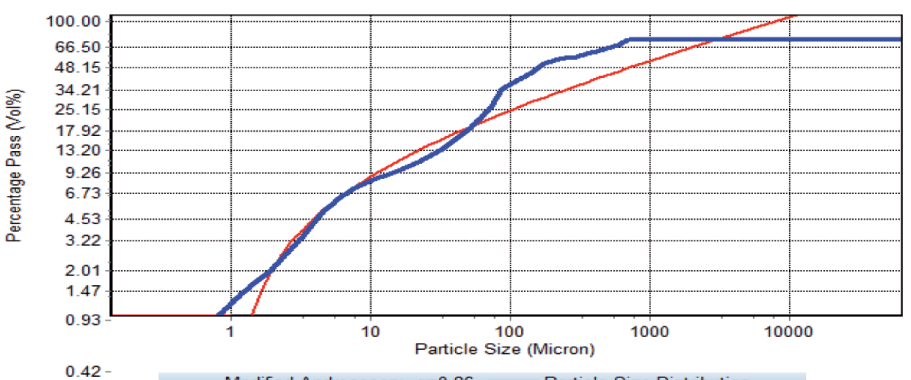

Fig. 6. Mix design for high performance concrete.

Table 5

Cube compressive strength of high performance concrete.

\begin{tabular}{|c|c|c|c|}
\hline \multirow{2}{*}{ Mix } & \multicolumn{3}{|c|}{ Cube Compressive Strength(N/mm $\mathbf{m}^{\mathbf{}}$ ) } \\
\cline { 2 - 4 } & 3 days & 7 days & 28 days \\
\hline High performance concrete & 27.11 & 42.13 & 47.53 \\
\hline
\end{tabular}

\section{Summary and Conclusions}

In this paper, optimized concrete mix is designed for normal strength and high performance concrete using particle packing method. A critical review of mix design methods using American Concrete Institute (ACI) and Bureau of Indian Standards (BIS) have been conducted highlighting the similarities and differences towards attaining a particular design compressive strength. Compression test has been carried out for cubes of M30 and M40 grade concrete. Optimization of concrete mix has been carried out by adjusting the concrete ingredients to match with the modified Anderson curve. Compression test has been carried out for the adjusted proportions and it is observed that the mixes designed by particle packing method estimates compressive strength closer to design compressive strength. Further, a mix has been designed for high performance concrete, which has a fine grained matrix and compression test has been performed to check the adequacy of desired compressive strength and found to be satisfactory.

\section{ACKNOWLEDGEMENT}

Authors thank Dr. G. S. Palani, Mr. S. Maheswaran and Mr. V. Ramesh kumar Scientists Miss. B. Bhuvaneshwari Quick Hire Fellow for the fruitful discussions during the study. The co-operation and support provided by staff of Advanced Material Laboratory for carrying out experiments is highly acknowledged. This paper is being published with the kind permission of the Director, CSIR-SERC. 


\section{REFERENCES}

1. ACI Committe211, (reapproved in 2002), Standard practice for selecting proportions for normal, heavyweight and mass concrete, American Concrete Institute, USA, 1991.

2. V. Johansen, P.J. Andersen, Particle Packing and Concrete Properties, Materials Science of concrete 2, American Ceramics Society, Inc., Westerville, Ohio, 111-147, 1996.

3. P. Goltermann, V. Johansen, L. Palbol, Packing of aggregate an alternative tool to dertermine the optimal aggregate Mix, ACI Material Journal, 94, 5, 435-443, 1997.

4. M.R. Jones, L. Zheng, M.D. Newlands, Comparison of particle packing models for proportioning concrete constituents for minimum voids ratio, Material and Structures, 35, 5, 301-309, 2002.

5. W. Aipin, Z. Chengzhi, Z. Ningsheng, Study of the influence of the particle size distribution on the properties of cement. Cement and Concrete Research, 29, 11, 685-695, 1997.

6. M. Santhanam, Using paticle packing approach towards reducing cement consumption in high performance concrete. ICI journal, 1, 4, 4-8, 2011.

7. S.H. Kosmatka, B. Kerkhoff, W.C. Panarese, Design and control of concrete mixtures, portland cement Association, Skokie, Illinois, USA, 2002.

8. SP: 23-1988, Handbook on concrete mixes, Bureau of Indian Standards, New Delhi, India, 1983.

9. IS-10262, 2009, Indian standard concrete mix proportioning - Guidelines (First revision), Bureau of India Standard, New Delhi, India.

10. IS-10262:1982, Indian Standard, Recommended guidelines for concrete mix design, Reaffirmed 2004, Bureau of Indian Standard, New Delhi, India.

11. H.C. Henry, Wong, K.H. Albert Kwan, Packing Density: A key concept for mix Design of high performance concrete, Department of Civil Engineering, The University of Hong Kong, Hong Kong.

12. P. Domone, C. Hsi-Wen, Testing of binders for high performance concrete. Cement and Concrete Research, 27, 8, 1141-1147, 1997.

13. N.Q. Feng, Y.X. Shi, T.Y. HaO, Influence of ultra fine powder on the fluidity and strength of cement paste, Advances in cement Research, 12, 3, 89-95, 2000.

14. C.C. Furnas, Grading Aggregates: I. Ind. Eng. Chem., 23, 1052-58, 1931.

15. F.O. AnderegG, Grading Aggregates II. Ind. Eng. Chem., 23, 1058-64, 1931.

16. A.H.M. Andreasen, J. Andersen, Ueber die beziehung zwischen Kornabstufung und Zwischenraum in produkten aus losen Kornern(mit einigen Experimenten). Kolloid-Zeitschrift 50, 217-228, 1930.

17. A.K.H. Kwan, Use of condensed silica fume for making high strength, self consolidating concrete, Candian Journal of Civil Engineering, 27, 4, 620-627, 2000.

18. A.K.H. Kwan, C.F. MoRA, Effects of various shape parameters on packing of aggregate particles. Magazine of concrete Research, 53, 2, 91-100, 2001.

Remarks on the paper should be sent to the Editorial Office

no later than June 30, 2007
Received August 15, 2011

revised version

December 17, 2011 